\title{
Annealing Effect on the SnSe Nanocrystalline Thin Films and the Photovoltaic Properties of the p-SnSe/n-Si Heterojunction Solar Cells
}

\author{
Ghuzlan Sarhan Ahmed*, Bushra K. H. Al-Maiyaly, Seham Hasan Salman, Rajaa Faisal Rabeea \\ Department of Physics, College of Education for Pure Science (Ibn-Alhaitham), University of Baghdad - Iraq
}

\section{Article information}

Article history:

Received: September, 01, 2021

Accepted: October, 18, 2021

Available online: October, 20, 2021

Keywords:

$\mathrm{SnSe}$

Thin films,

Solar cells,

Annealing

\section{*Corresponding Author:}

Ghuzlan Sarhan Ahmed

ghzlan82sn@gmail.com

DOI:

https://doi.org/10.53523/ijoirVol8I2ID68

\begin{abstract}
A thin film of SnSe were deposited by thermal evaporation technique on $400 \pm 20 \mathrm{~nm}$ thick glass substrates of these films were annealed at different temperatures $\left(100,150,200{ }^{\circ} \mathrm{C}\right)$, The effect of annealing on the characteristics of the nano crystalline SnSe thin films was investigated using XRD, UV-VIS absorption spectroscopy, Atomic Force Microscope (AFM), and Hall effect measurements. The results of X-ray displayed that all the thin films have polycrystalline and orthorhombic structure in nature, while UV-VIS study showed that the SnSe has direct band gap of nano crystalline and it is changed from 60.12 to $94.70 \mathrm{~nm}$ with increasing annealing temperature. Hall effect measurements showed that all the films have a positive Hall coefficient, which means that the conductivity of the films is p-type. The conductivity of $\mathrm{SnSe}$ films was increased with increasing annealing temperatures (except that at $200^{\circ} \mathrm{C}$ ). The I-V characteristics under illumination for the "p-SnSe/nSi" solar cell displayed an increase in conversion efficiency with increasing annealing temperature from R.T to $150^{\circ} \mathrm{C}$, while at $200^{\circ} \mathrm{C}$, this efficiency was decreased. The measurements of the $\mathrm{C}-\mathrm{V}$ characteristics displayed that all junctions were abrupt type. It is clear from $\mathrm{C}-\mathrm{V}$ measurements that the capacitance decreased with increasing reverse bias voltage which leads to an increase in the depletion width.
\end{abstract}

\section{Introduction}

Tin Selenide (SnSe) is of considerable interest owing to having potential solar cell applications [1], and orthorhombic crystal structure [2]. Thin film Tin Selenide is a chemically stable material, and an earth abundant. It can be prepared in a possible large-scale, therefore, it can be a good candidate in solar cells fabrication. Several researchers have used several preparation methods to prepare SnSe, such as: thermal evaporation [3], spin coating [4], flash evaporation [5], Hot wall epitaxy [6, 7], and spray pyrolysis [8]. Ghuzlan S. Ahmed et al. [9] have investigated pure SnSe thin films and doped SnSe thin films with sulphur at doping concentrations of 0, 3, 5, and 7\%. In this paper, SnSe films were prepared using thermal evaporation technique. The effect of thermal annealing on the properties of the opto-electrical properties of these films was investigated.

\section{Experimental Procedure}

This work contains the preparation of thin films SnSe using the coating unit model for thermal evaporation technique (Edward 306) were observed using diffract meter system XRD with voltage and current (10Kv and 
$20 \mathrm{~mA}), \mathrm{Cu} \mathrm{K} \alpha$ radiation $(\lambda=1.5418 \AA)$, after mixing Tin and Selenium elements with high purity (99.99\%) for both of them in a ratio $(1: 1)$ in tube of quartz and heated at $\left(1000^{\circ} \mathrm{c}\right)$ for five hours according to the diagram phase of SnSe is cooled and to take the material powder and placed it on a boat to form a homogeneous melt. This alloy was used in preparation of SnSe thin films, the glass substrate was ultrasonically cleaned 15 minutes in ethanol and then 15 minutes in distilled water, While Silicon wafers immersed and moved for 1-2 minutes in a chemical solution of diluted hydrofluoric acid HF with ratio (1:10) HF to water to remove the oxide layer which is generated as a result of weather conditions, then washed with distilled water, after that the wafers dried using soft paper. The films thickness is $(400 \pm 20) \mathrm{nm}$. These films were annealed at different temperatures $(100,150$, and 200$){ }^{\circ} \mathrm{c}$ for one hour. The electrical conductivity of these films has been measured as a function of temperature ranged (293423)K via utilizing critical digital electro-meter (Keighley 616), and electrical furnace, The features of I-V measurements as a function of forward and reverse bias voltage were performed for all films using D.C power supply and (Keithly digital electrometer 616) to found the parameters of solar cell like, short circuit current density (Jsc), open circuit voltage (Voc), maximum current (Im), Fill Factor (FF), and quantum efficiency ( $\eta$ ). C-V have been measured as a function of reverse bias voltage at a ranging from $0.1-2 \mathrm{~V}$ with a constant frequency of $10 \mathrm{kHz}$ utilizing (LCR meter GW instek 8105G).

\section{Results and Discussion}

\subsection{Structural Analysis}

The XRD patterns for the annealed and deposited of SnSe thin films are shown in Table (1) displays the XRD parameters of the as-deposited and annealed samples. The preferred orientation in the (111) plane and crystallinity are improved with increasing annealing temperature up to $150^{\circ} \mathrm{C}$, then drops at $200^{\circ} \mathrm{C}$, because the structure of this films is approaching the random, which has changed some of its properties as shown in Figure (1). That means after annealing, the XRD characteristic peaks get sharper, indicating that the Nano crystalline size which is define in a polycrystalline film can be estimated by using the Scherer formula is increased. The parameters of the lattice are calculated with the Scherer's equation from the fitting of the least square to the Bragg peaks [9]:

$$
C . S=\frac{0.94 \lambda}{\beta \operatorname{Cos} \theta}
$$

where: $\lambda$ is the XRD wavelength, $\beta$ : is the peaks of the FWHM, and $\theta$ : is the Bragg's angle.

Table (1). Parameters of SnSe thin films with various annealing temperatures.

\begin{tabular}{|c|c|c|c|c|c|}
\hline $\mathbf{T}\left({ }^{\mathbf{}} \mathbf{C}\right)$ & $\mathbf{2 \theta}$ & $\begin{array}{c}\mathbf{d}_{\text {hkl }} \\
(\mathbf{e x p})\end{array}$ & $\mathbf{d h k l}(\mathbf{s t d})$ & $\mathbf{C . S}(\mathbf{n m})$ & Hkl \\
\hline As-deposited & 30.419 & 2.932 & 2.936 & 18.167 & $\mathbf{( 1 1 1})$ \\
\hline 100 & 30.431 & 2.932 & 2.934 & 20.352 & $\mathbf{( 1 1 1 )}$ \\
\hline 150 & 30.29 & 2.924 & 2.915 & 27.675 & $\mathbf{( 1 1 1 )}$ \\
\hline 200 & 30.426 & 2.949 & 2.932 & 22.152 & $\mathbf{( 1 1 1 )}$ \\
\hline
\end{tabular}



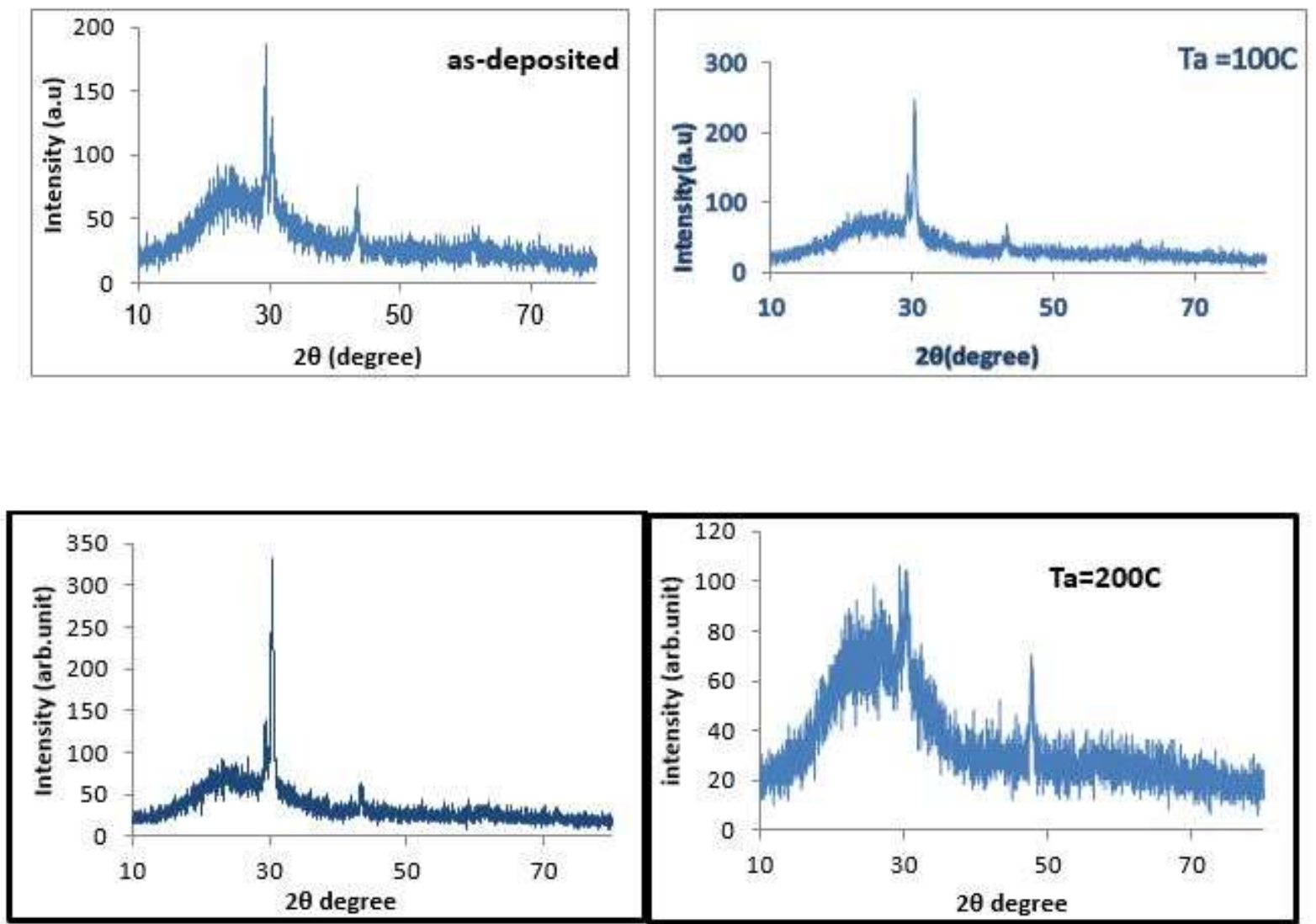

Figure (1). XRD of SnSe thin films with different annealing temperatures.

\subsection{The Optical and Electrical Characterization}

Figure (2) shows the absorbance with wavelength for SnSe films at different annealing temperatures. Table (2) shows the variation of optical energy band gap (Eg) with the annealing temperature, from this table. The Eg increases when annealing temperatures increases because of the reduction of the density and the tails of the localized states in the thermally annealed films, which agrees with references $[10,11]$. This led to the use of these films in photovoltaic applications as an absorber layer.

Table (2). Optical band gap at $\lambda=825 \mathrm{~nm}$ of SnSe films.

\begin{tabular}{|c|c|}
\hline Sample & $\mathbf{E g}_{\mathrm{g}}(\mathbf{e V})$ \\
\hline Pure & 1.5 \\
\hline $\mathbf{1 0 0}^{\mathbf{}} \mathbf{C}$ & 1.7 \\
\hline $\mathbf{1 5 0}^{\mathbf{}} \mathbf{C}$ & 1.85 \\
\hline $\mathbf{2 0 0}^{\circ} \mathbf{C}$ & 2.2 \\
\hline
\end{tabular}




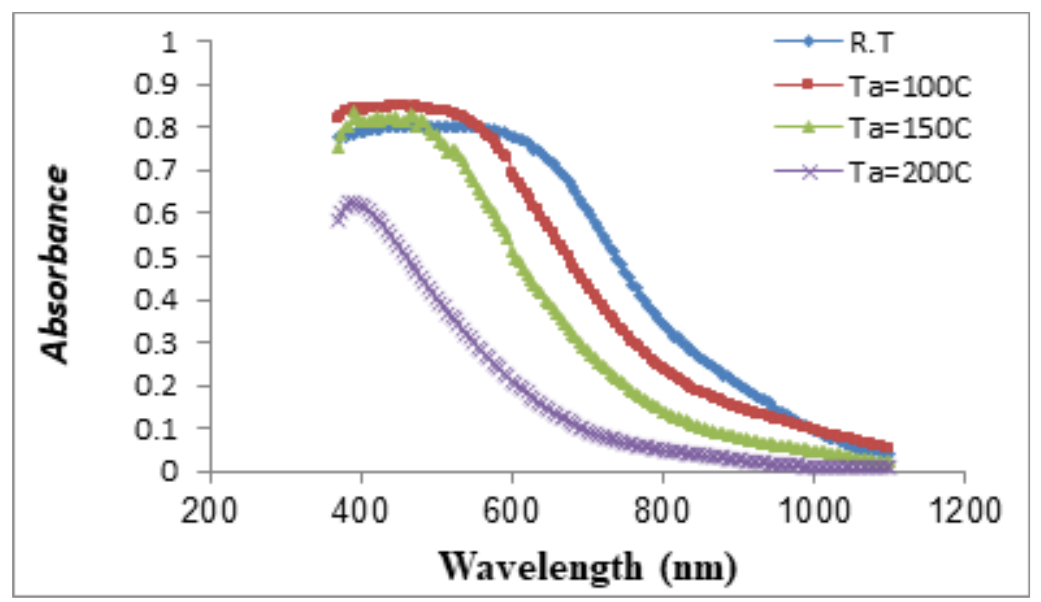

Figure (2). The absorbance with wavelength for SnSe films at different annealing temperatures.

Figure (3) shows the DC conductivity variation of the SnSe films versus the reciprocal of temperature at different annealing temperature $\left(\left(100,150\right.\right.$-and $\left.200^{\circ} \mathrm{C}\right)$. The activation energy values were calculated using the following equation [12]:

$$
\sigma=\sigma_{o} \cdot \exp \left(-E_{a} / k_{B} T\right)
$$

Where $\sigma 0$ is the electrical conductivity which its minimum is at $0 \mathrm{~K}, \mathrm{Ea}$ : is the activation energy, which will be discussed elsewhere in Table (4), It is obvious from this table that there were two activation energies (Ea1 and Ea2) due to two transporting mechanisms throughout the temperature range (300-475K, From the measurements of D.C current, it is shown that the conductivity increases with rising temperature (except for $200^{\circ} \mathrm{C}$ ). This is because of the behaviour of the semiconductors due to their resistance because of the negative thermal coefficient. The conduction mechanism of the activation energy Ea1 at temperatures in the range (300-415 K) is due to carrier's excitation into every localized state close to the valence and conduction bands. While at higher temperatures (425$475 \mathrm{~K}$ ) the activation energy Ea2, is due to the carrier excitation into the extended states beyond the mobility edge [13].

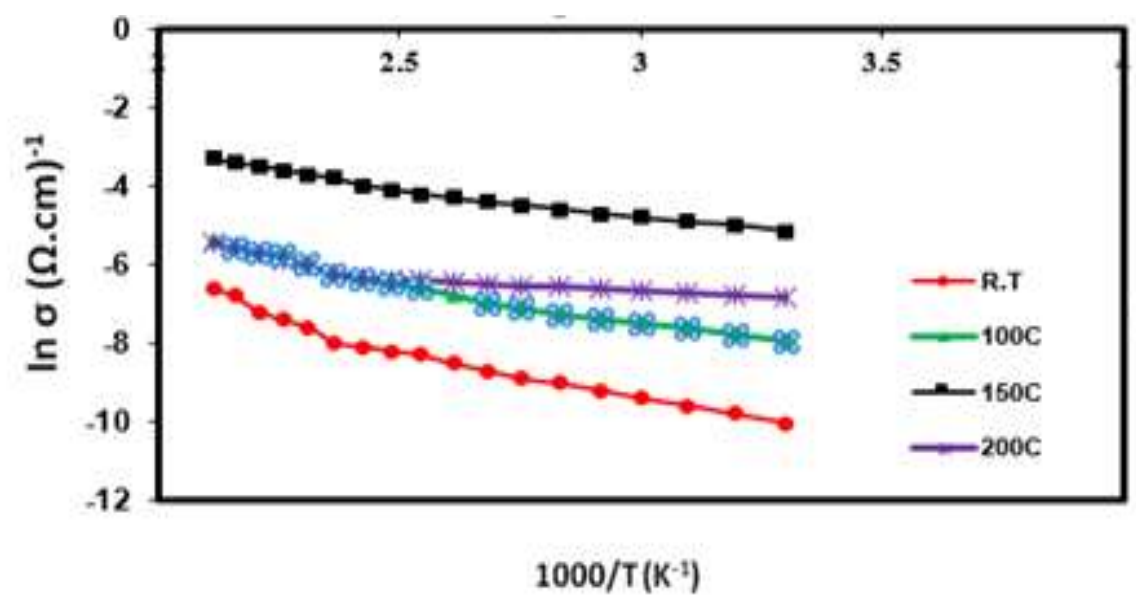

Figure (3). $\operatorname{Ln}(\sigma)$ versus 1000/T for SnSe films at different annealing temperatures. 
Table (3). The conductivity and the activation energy for SnSe films.

\begin{tabular}{|c|c|c|c|}
\hline Sample & $\boldsymbol{\sigma}(\mathbf{\Omega . c m})^{-\mathbf{1}}$ & $\begin{array}{c}\mathbf{E}_{\mathbf{a} 1}(\mathbf{e V}) \\
\text { At }(\mathbf{3 0 0 - 4 1 5 K})\end{array}$ & $\begin{array}{c}\mathbf{E}_{\mathbf{a} 2}(\mathbf{e V}) \\
\text { At }(\mathbf{4 2 5}-\mathbf{4 7 5 K})\end{array}$ \\
\hline Pure & $3.720 * 10^{-6}$ & 0.27778 & 0.047902 \\
\hline $\mathbf{1 0 0}$ & $1.710 * 10^{-4}$ & 0.4644 & 0.19178 \\
\hline $\mathbf{1 5 0}$ & $2.293 * 10^{-2}$ & 0.171991 & 0.10492 \\
\hline $\mathbf{2 0 0}$ & $1.567 * 10^{-3}$ & 0.28552 & 0.15222 \\
\hline
\end{tabular}

Hall measurements were carried out to determine the conductivity type of the charge carriers, and to calculate Hall coefficient $(\mathrm{RH})$, Hall mobility $(\mu \mathrm{H})$, and carriers' concentration $(\mathrm{nH})$ through the following equations:

$$
\begin{aligned}
& R_{H}=\frac{+1}{n q} \ldots \ldots \ldots \ldots \ldots \ldots \ldots \ldots \text { for }(p-\text { type }) \\
& R_{H}=\frac{-1}{n q} \ldots \ldots \ldots \ldots \ldots \ldots \ldots \ldots \text { for }(n-\text { type }) \\
& R_{H}=\left(\frac{V_{H}}{I}\right) \times \frac{t}{B} \\
& \mu_{H}=\frac{\sigma}{n_{H} q}=\sigma\left|R_{H}\right|
\end{aligned}
$$

where q: is the electron charge, $\mathrm{B}$ is the magnetic field intensity (Tesla), and $\mathrm{nH}$ is the carrier's concentration. These values are tabulated in Table (4). It is observed that all of the films have a Hall coefficient with a positive sign, which means that the conductivity of films is a p-type in nature. The carrier concentration and Hall mobility of SnSe films increased when increasing the annealing temperature (except for $200^{\circ} \mathrm{C}$ ). This is due to the increase in grain boundaries and the structural defects of the films [14].

Table (4). Hall Effect measurements for SnSe at different annealing temperatures and different doping ratios.

\begin{tabular}{|c|c|c|c|}
\hline Sample & $\mathrm{R}_{\mathrm{H}}\left(\mathrm{m}^{3} / \mathrm{c}\right)$ & $\mu_{\mathrm{H}}\left(\mathrm{cm}^{2} / \mathrm{v} . \mathrm{s}\right)$ & $\mathrm{n}_{\mathrm{H}}\left(\mathrm{cm}^{-3}\right)$ \\
\hline Pure & $7.829 \times 10^{4}$ & 19.86 & $1.1711 \times 0^{12}$ \\
\hline $100^{\circ} \mathrm{C}$ & $5.332 \times 10^{6}$ & $5.2851 \times 0^{1}$ & $2.0231 \times 0^{13}$ \\
\hline $150^{\circ} \mathrm{C}$ & $3.089 \times 10^{5}$ & $1.7961 \times 0^{3}$ & $7.9831 \times 0^{13}$ \\
\hline $200^{\circ} \mathrm{C}$ & $1.4880 \times 10^{5}$ & $2.3351 \times 0^{2}$ & $4.1951 \times 0^{13}$ \\
\hline
\end{tabular}

\subsection{Photovoltaic Characteristics of p-SnSe/n-Si Heterojunction Solar Cell}

Figures $(2 \& 3)$, illustrate the I-V characteristics of SnSe/Si heterojunctions in the dark and under illumination and at various annealing temperatures. The forward dark current is dominated by the majority carriers, and applied voltage injects majority carriers, which is responsible for decreasing the built-in potential value and the depletion 
width layer from these figures, it is observed that the current rises with the rising annealing temperatures, Annealing can cause a re-arrangement in the atoms at the interface and leads to enhancing the junction properties. These results agree with literature [16]. The solar cell parameters (namely: Jsc, Vm, Voc, Im, F.F, and $\eta$ ), are tabulated in Table (5). The table shows that the efficiency increases with increasing annealing temperatures then decreases at higher temperatures, (i.e. $200{ }^{\circ} \mathrm{C}$ ), The as-prepared cell gives efficiency of $1.066 \%$, then efficiency increases up to $4.26 \%$ at $150^{\circ} \mathrm{C}$, and then drops back to $2.89 \%$ at $200^{\circ} \mathrm{C}$.

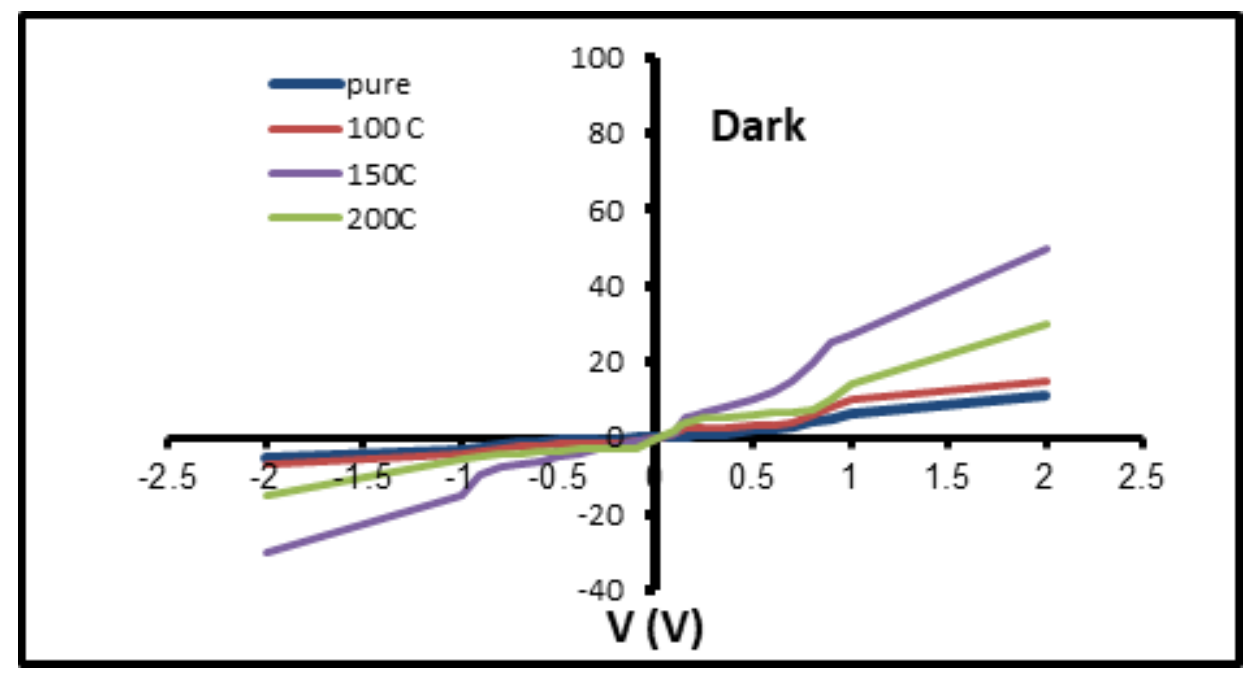

Figure (4). The I-V characteristics in the dark for $\mathrm{SnSe} / \mathrm{Si}$ cells at different annealing temperatures.

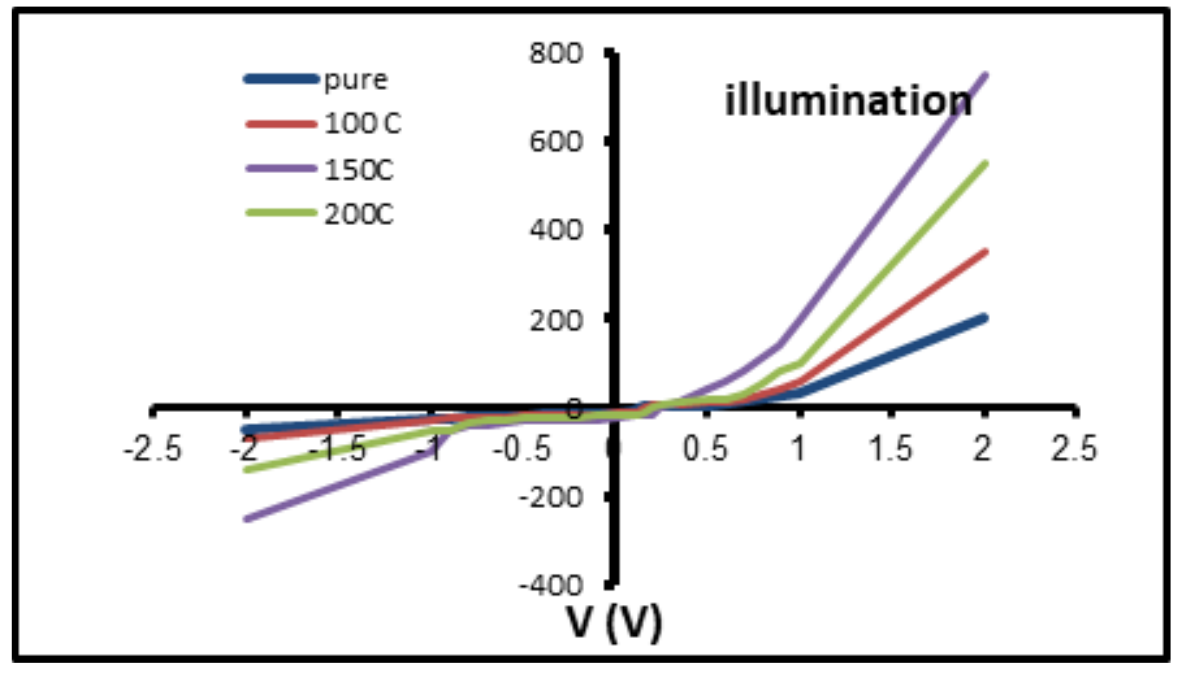

Figure (5). I-V characteristics of the illuminated SnSe/Si cells at different annealing temperatures.

Table (5). The photovoltaic parameters of $\mathrm{SnSe} / \mathrm{Si}$ cells at different annealing temperatures.

\begin{tabular}{|c|c|c|c|c|c|c|}
\hline Sample & $\begin{array}{c}\mathrm{V}_{\text {oc }} \\
(\mathrm{V})\end{array}$ & $\begin{array}{c}\mathrm{J}_{\mathrm{sc}} \\
\left(\mathrm{mA} / \mathrm{cm}^{2}\right)\end{array}$ & $\begin{array}{c}\mathrm{V}_{\mathrm{m}} \\
(\mathrm{V})\end{array}$ & $\begin{array}{c}\mathrm{I}_{\mathrm{m}} \\
(\mathrm{mA})\end{array}$ & F.F & $\eta \%$ \\
\hline Pure & 0.12 & 12 & 0.1 & 8 & 0.55556 & 1.066 \\
\hline $100 \mathrm{C}$ & 0.16 & 12.5 & 0.125 & 9 & 0.5625 & 1.5 \\
\hline $150 \mathrm{C}$ & 0.25 & 21 & 0.2 & 16 & 0.609524 & 4.26 \\
\hline $200 \mathrm{C}$ & 0.2 & 18 & 0.155 & 14 & 0.602788 & 2.89 \\
\hline
\end{tabular}


Figure (6) shows the C-V characteristics of the junction It is clear from Figure (6a) that the capacitance decreases with increase annealing temperatures, This behaviour happens because of the increase in the depletion layer width that leads to increasing the interior potential as a result of the enhancement in the crystal structure of the films [17], while figure (6b)show the plot reveals straight line relationship which means that all junctions were of an abrupt type, The interception of the straight line with the voltage axis at $(1 / \mathrm{C} 2=0)$ represents the built-in potential as tabulated in Table (6).

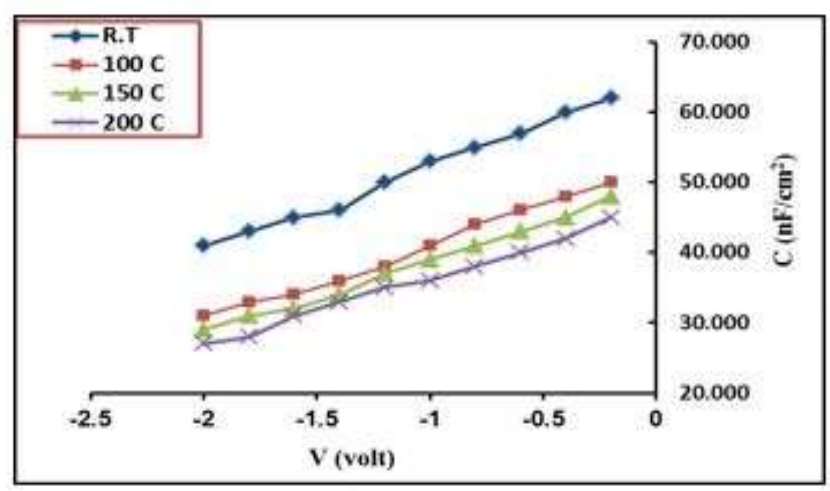

(a)

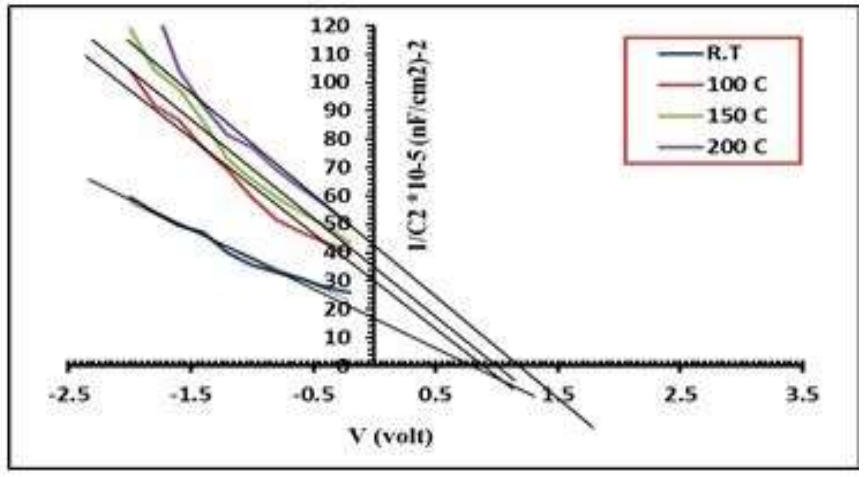

(b)

Figure (6). (a) Capacitance against reverse bias voltage, (b)the $1 / \mathrm{C}^{2}$ as a function of reverse bias voltage for "SnSe /Siheterojunction at various annealing temperatures.

Table (6). The values of $\left(\mathrm{C}_{\mathrm{o}}, \mathrm{W}, \mathrm{N}_{\mathrm{d}}\right.$, and $\left.\mathrm{V}_{\mathrm{bi}}\right)$ for "SnSe/Si" heterojunction solar cells at different annealing temperatures and doping concentrations.

\begin{tabular}{|c|c|c|c|c|}
\hline Sample & $\mathrm{C}_{\mathrm{o}}\left(\mathrm{nF} / \mathrm{cm}^{2}\right)$ & $\mathrm{W}(\mathrm{nm})$ & $\mathrm{N}_{\mathrm{d}}\left(\mathrm{cm}^{-3}\right)$ & $\mathrm{V}_{\text {bi }}($ Volt $)$ \\
\hline Pure & 70.7106781 & 79.4827 & $1.87392 \times 10^{16}$ & 0.8 \\
\hline $100^{\circ} \mathrm{C}$ & 55.9016994 & 84.97058 & $2.00258 \times 10^{16}$ & 0.95 \\
\hline $150^{\circ} \mathrm{C}$ & 53.4522484 & 88.86436 & $2.25715 \times 10^{16}$ & 1.05 \\
\hline $200^{\circ} \mathrm{C}$ & 47.1404521 & 100.7627 & $2.49503 \times 10^{16}$ & 1.15 \\
\hline
\end{tabular}

Figure (7) indicates the AFM for these films which shows each film exhibits grains of nano size packed jointly spread across the surface of the substrate with no pinholes in uniform fashion. The average grain size increases as the annealing temperature increasing except at $200^{\circ} \mathrm{C}$, which agree with XRD results. The results of AFM are tabulated in Table (7). 

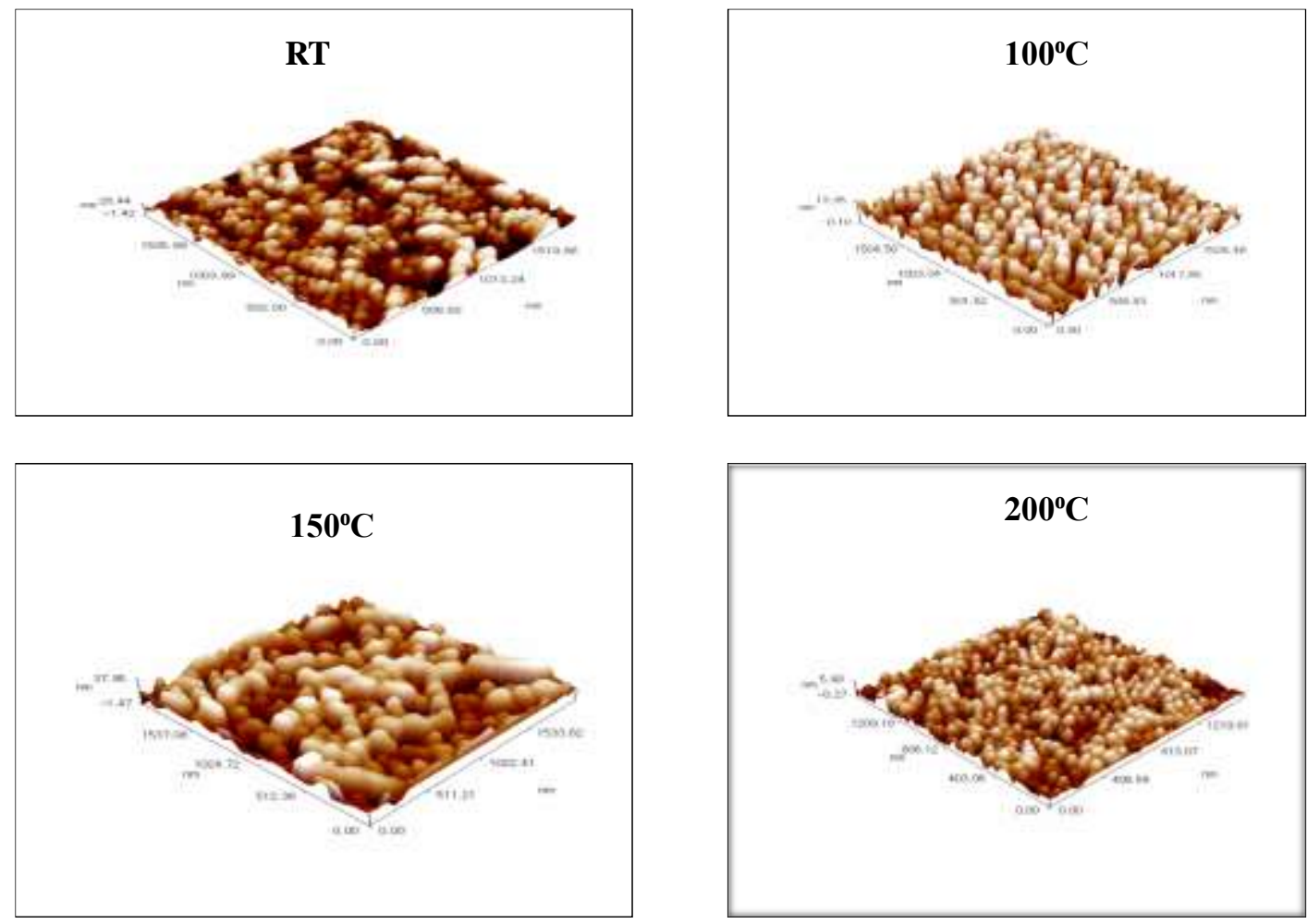

Figure (7). AFM images for SnSe films at difference annealing temperatures.

Table (7). The average grain size and roughness of SnSe thin films at different annealing temperature.

\begin{tabular}{|c|c|c|c|}
\hline $\mathrm{T}\left({ }^{\circ} \mathrm{C}\right)$ & $\begin{array}{c}\text { Roughness average } \\
(\mathrm{nm})\end{array}$ & $\begin{array}{c}\text { r.m.s } \\
\text { roughness }(\mathrm{nm})\end{array}$ & $\begin{array}{c}\text { Grain } \\
\text { size(nm) }(\mathrm{nm})\end{array}$ \\
\hline$($ R.T $)$ & 3.1 & 3.63 & 60.12 \\
\hline $100^{\circ} \mathrm{C}$ & 7.4 & 8.55 & 65.26 \\
\hline $150^{\circ} \mathrm{C}$ & 9.31 & 10.6 & 94.70 \\
\hline $200^{\circ} \mathrm{C}$ & 1.31 & 1.54 & 65.77 \\
\hline
\end{tabular}

\section{Conclusions}

The XRD results displayed that the SnSe films deposited by thermal evaporation and annealed at various temperatures, were polycrystalline of orthorhombic structure and preferentially orientated along (111) direction. The results of AFM displayed that the size grain and roughness of SnSe films increased with increasing annealing temperatures except at $200^{\circ} \mathrm{C}$. The optical energy band gap increases with increasing annealing temperatures. I$\mathrm{V}$ characteristics of the "SnSe/n-Si hetrojunctions show an increase in the dark current with increasing the annealing temperatures (except for $200^{\circ} \mathrm{C}$ ) at last. $\mathrm{C}-\mathrm{V}$ data indicate that all junctions were abrupt.

\section{References}

[1] A. Agarwal, M. N. Vashi, D. Lakshmi Narayana, "Electrical resistivity anisotropy in layered p-SnSe single crystals", J. of Mater Sci Mater Electron, vol.11, no1, pp.67, 2000,

[2] K. S. Urmila, T.A. Namitha, et al, "Optoelectronic properties and Seebeck coefficient in SnSe thin films", J. of semiconductors, vol.37, no.9: pp.1-6, 2016.

[3] N. Kumar, U. Parihar, et al. "Effect of film thickness on optical properties of Tin Selenide thin films prepared by thermal evaporation for photovoltaic Applications", American J. of materials, vol.2, no, 1, pp. 41-45, 2012. 
[4] Ghuzlan Sarhan Ahmed, and Bushra K.H. Al-Maiyaly, "Cu doping effect on characterization of Nano crystalline SnSe thin films", Vol. 2190, No. 1, p. 020019. AIP Publishing LLC, 2019.

[5] S. Ilican, Y. Caglar, and M. Caglar. "Preparation and characterization of $\mathrm{ZnO}$ thin films deposited by sol-gel spin coating method", Journal of optoelectronics and advanced materials, vol.10, no. 10, pp.2578-2583, 2008.

[6] G. H. Chandra, J. Naveen Kumara, N.M. Raob, and S. Uthanna, "preparation and characterization of flash evaporated tin selenide thin films", J. of Cryst. Growth, vol. 306, no.1, pp.68-74, 2007.

[7] J. P. Singh, and R. K. Bedi. "Tin selenide films grown by hot wall epitaxy", Journal of applied physics, vol.68, no. 6 , pp.2776-2779, 1990.

[10] R. M. G. G. Mariappan, M. Ragavendar, and G. Gowrisankar, "Growth and characterization of SnSe thin films prepared by spray pyrolysis technique", Chalcogenide Letters, vol. 7, no. 3: pp211-216, 2010.

[11] G. S. Ahmed, B. K. Al-Maiyaly, B. H. Hussein, H. K. Hassun, "Opto-electrical properties of p-SnSe: S/N-Si heterojunction for solar cell application”, AIP Conference Proceedings, vol. 2307, no. 1, pp. 020026, 2020.

[12] Z. Zainal, N. Saravanan, K. Anuar, and Mohd Z. Hussein, "Chemical path deposition of tin selenide thin films", Mater. Sci. Eng. B, vol. 107, no.2, pp. 181-185, 2004.

[13] Amer Abbas Ramadhan, "Structural, Optical and photovoltaic Effect of Thermal Evaporated Tin Selenide Thin Films", Thesis, University of Baghdad. 2013.

[14] Yue-Xing Chen, Zhen-Hua Ge, Meijie Yin, Dan Feng, Xue-Qin Huang, Wenyu Zhao, and Jiaqing He, "Understanding of the Extremely Low Thermal Conductivity in High-Performance Polycrystalline SnSe through Potassium Doping", (2016), J. of Advanced Functional Materials, p.1-10.

[15] A. Islam, M. Islam, M. Choudhury and M. Hossan, "Recent Development in Condenced Matter Physics and Nuclear Science, Rajshahi University, Bangladesh, pp.1969, 1998.

[16] M. Ohyama, "Electrical and optical properties of GaSe Thin films", J. Mater. Sci. Technol, vol.13, pp.299301, 1997.

[17] K. F. Abd El-Rahman, A.A.A. Darwish, E. A. A. El-Shazly, "Electrical and photovoltaic properties of SnSe/Si heterojunction", J. of Materials Science in semiconductor processing, vol.25, pp. 123-129, 2013.

[18] N. K. Kwok, Complete guide to Semiconductor Devices, 2nd Edition, Wiley-IEEE Press, U.S.A., 2002. 